\title{
Morphology of sesamoid bones in keyboard musicians
}

\author{
K.P. Dąbrowski ${ }^{1}$, H. Stankiewicz-Jóźwicka², A. Kowalczyk¹, J. Wróblewski², B. Ciszek¹,3 \\ ${ }^{1}$ Department of Descriptive and Clinical Anatomy, Medical University of Warsaw, Poland \\ ${ }^{2}$ The Instrumental Department, The Fryderyk Chopin University of Music, Warsaw, Poland \\ ${ }^{3}$ Department of Neurosurgery in Bogdanowicz Children's Hospital, Warsaw, Poland
}

[Received: 7 April 2020; Accepted: 29 May 2020]

Background: The sesamoid bones are small, usually oval bone structures often found in joints and under the tendons. Although their precise function is not fully understood, it is agreed upon that they protect the joints and make movements faster and less energy consuming. Sesamoid bones are found in hands, especially around first, second and fifth metacarpophalangeal joint and the interphalangeal joint of the thumb.

Materials and methods: This study compares a group of 32 young musicians to 30 non-musicians of similar age and posture. The hands of the subjects were examined by ultrasound imaging for the presence of sesamoid bones. The results were noted and observed sesamoids were measured.

Results: The results seem to prove that although there are no difference in the amount or the location of the sesamoid bones between the musicians and the non-musicians, there is statistically significant tendency for the musicians to have bigger sum of the sesamoid's volume per hand (Fisher's test p-value $=0.034<0.05$ ). Conclusions: There was also observed an unusually shaped "Bactrian" sesamoid bone at the interphalangeal joint of the thumb in 8 cases in the musicians' group and 1 case in the control group. All participants with the aforementioned structure were female. (Folia Morphol 2021; 80, 2: 410-414)

Key words: sesamoid, wrist, hand, musician, morphology, adaptation

\section{INTRODUCTION}

First known descriptions of the Sesamoid bones come from Galen's works on Old World monkeys, most likely macaques, in the late second century. More reliable account comes from Versalis' De Humani Corporis Fabrica Libri Septem of 1542. Both authors, however, describe the Sesamoid bones as small, oval, bony structures forming in close vicinity of joints - either within the joint capsule walls or under or within tendons of nearby muscles, most noticeably on palmar side of a hand and plantar side of a foot. Their name comes from resemblance in size and shape to sesamoid seeds, although they are also being compared to halves of peas or grains of rice $[2,9,12,22,23,25]$.

The prevalence of Sesamoid bones seems to vary greatly depending on ethnicity, it is safe to say, however, that in over $99 \%$ of cases there are two bones present in the first metacarpophalangeal joint, vast majority of population possesses Sesamoid bones in the fifth metacarpophalangeal joint and first interphalangeal joint and approximately $50 \%$ of peo- 
ple have a sesamoid bone in the second metacarpophalangeal joint. They can also occur in other joints of the hand and fingers, but that remains very rare $[1,2,9,10,12,13,17,19,25]$.

The precise function of Sesamoid bones remains a subject of discussions. It is generally agreed that they play part in protecting the joint, reducing pressure and friction of the tendon and modifying the vector of the muscular pull $[1,5,8,9,12,18,25]$.

\section{MATERIALS AND METHODS}

The study was performed on the group of 62 healthy adults: a study group of 32 students of keyboard instruments and a control group of 30 students without any extended musical training.

The study group included 16 females and 16 males between the ages of 18 and 38 , with a mean age of 23.7 years, mean height of $172.8 \mathrm{~cm}$ and mean weight of $67.3 \mathrm{~kg}$. Five of them were noted as left-handed. All of the participants were healthy and had no history of serious trauma or surgical procedures in the area of the hand. All the participants underwent multiple years of instrumental training.

The control group included 17 females and 13 males between the ages of 20 and 33, with a mean age of 22.8 years, mean height of $174.3 \mathrm{~cm}$ and mean weight of $69.2 \mathrm{~kg}$. Four of them noted as left-handed. All of the participants were healthy and had no history of serious trauma or surgical procedures in the area of the hand. None of the participants underwent any form of prolonged, systematic musical education.

All of the examined signed the form of informed consent. All participants were interviewed and had the anthropological measurements of their upper extremities taken. Afterwards all of the participants' hands were examined by an ultrasound imaging (LOGIQ F8 GE with L6-12, 6-13 MHz probe) for presence of the sesamoid bones. Found bones were described regarding their amount, location and three-dimensional measurements (anterior-posterior, radial-ulnar and proximal-distal in relation to anatomical position). To facilitate comparison, the formula of the volume of the sesamoid bones was rounded to the product of the measurements. All the measurements and calculations were performed by the same team. All the findings were examined with the use of Fisher's exact test and t-Student's test.

The examination was completely non-invasive and the research does have the approval of the Ethics Committee.

\section{RESULTS}

The amount of sesamoid bones found in one hand varied from 2 to 6 with no significant differences between sides and groups (Fisher's test p-value for control group sides, study group sides, left hands of both groups and right hands of both groups, respectively: $0.654,0.683,0.398$, and 0.926 ) with 26 out of 32 musicians showing symmetry in the pattern, and 23 out of 30 non-musicians showing symmetry in the pattern. There was also no noticeable difference between the groups in the location of the sesamoid bones.

The mean of the sum of the sesamoid bones' volume in one hand for musicians was $83.2351 \mathrm{~mm}^{3}$ $\left(78.3774 \mathrm{~mm}^{3}\right.$ for the left hand and $88.0928 \mathrm{~mm}^{3}$ for the right hand) and for non-musicians was $74.8420 \mathrm{~mm}^{3}$ (73.5829 $\mathrm{mm}^{3}$ for the left hand and $76.1010 \mathrm{~mm}^{3}$ for the right hand). Fisher's test $\mathrm{p}$-value for the mean volumes from both hands was: $p$-value $=0.033618274$ ( $p$-value $=0.168077962$ for only left hands and $p$-value $=0.024897613$ for only right hands) which does reach the threshold of statistical significance ( $\alpha=0.05$ ).

In case of 27 musicians it was possible to acquire information regarding the length of their musical education and the starting age. The mean age of the beginning of the musical education was 7.7 years and the mean length of education to the point of examination was 15.4 years. Both of those variables, when tested against mean sum of the volumes of the sesamoids in one hand with paired t-Student's test has returned $p$-value $<0.0001$ which would suggest a strong correlation.

Sexual dimorphism proved to be statistically significant ( $p$-value $<0.05$ ) in musicians (Fisher's test $p$-value for mean, left hands and right hands respectively 0.003094, 0.025887, and 0.001637), with males having greater volume sum of sesamoid bones, and non-significant in control group (Fisher's test $p$-value for mean, left hands and right hands, respectively $0.636599,0.668857,0.110638$ ).

An unusually shaped, "Bactrian" sesamoid bone was observed in the first interphalangeal joint in musician's hand in 8 cases (5 females), 6 of which (3 females) occurred symmetrically. Only 1 case (left hand of a 23-year-old left handed female) was observed in the control group (Figs. 1, 2).

\section{DISCUSSION}

The features of a "perfect musician's hand" remain a subject of discussion. Most authors seem to focus 


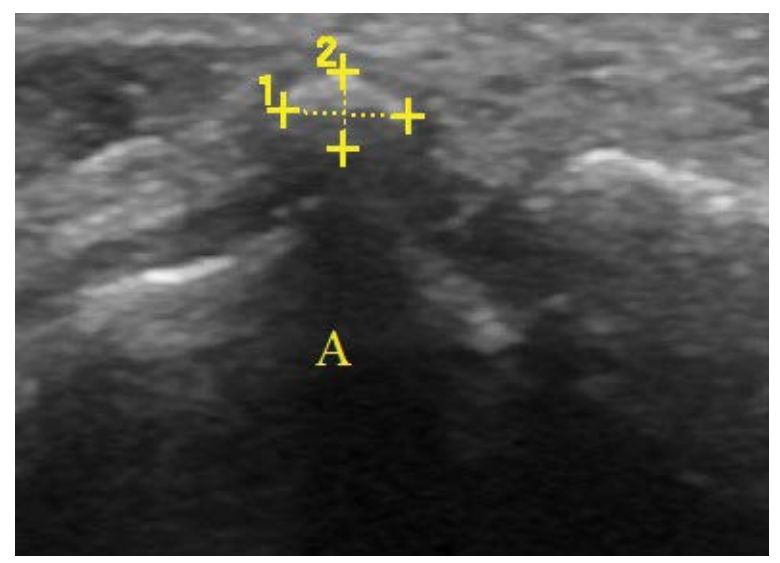

Figure 1. A sesamoid bone over the $5^{\text {th }}$ metacarpophalangeal joint (A) of the left hand of the female pianist - sagittal view. Estimated volume based on the measurements for this sesamoid bone was $19.2 \mathrm{~mm}^{3}$.

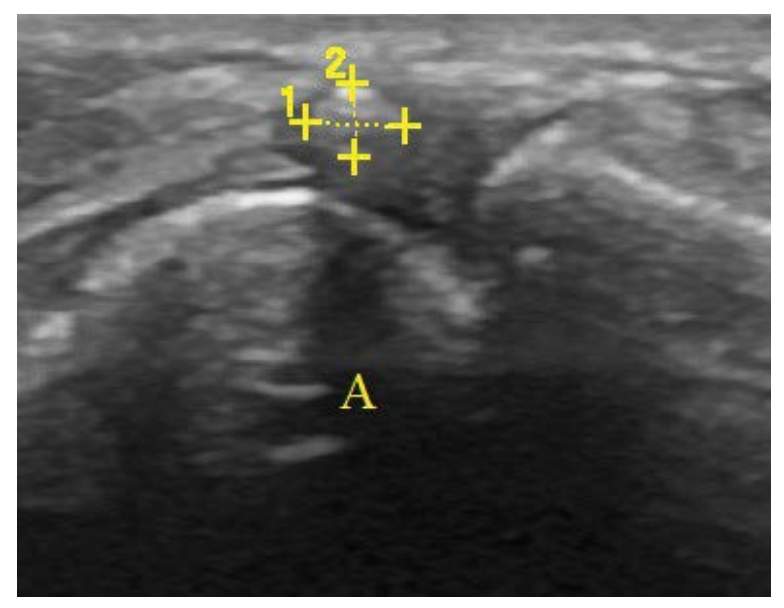

Figure 2. A sesamoid bone over the $5^{\text {th }}$ metacarpophalangeal joint (A) of the left hand of the female non-pianist of similar age, built and height as the aforementioned female pianist — sagittal view. Estimated volume based on the measurements for this sesamoid bone was $10.9 \mathrm{~mm}^{3}$.

primarily on the hand's size and the hand's span, with assumption that the bigger the hand and the hand span, the better. Wristen claims that throughout history small-handed musicians remained rather devoted amateurs than professionals [24]. Some authors point out that the group most commonly suffering from trauma and performance related misuse of the hands are women [16] who statistically have 15\% smaller hand than the men [4]. However, there seems to be a lot of research putting this seemingly obvious matter in question. The results of Sang-Hie Lee's research suggests that the size of the hand is not as important as it's mobility and hand's span, which seems to be less important of the two. She quotes Kentner saying that there were just as many famous pianists with big hands (like Sauer, Richter, Rachmaninoff) as those whose hands were considered small (Patchmann, Hoffmann, d'Albert). Both Sang-Hie $[15,16]$ and Sakai [14] bring up Wagner's analysis - that hands of the male pianists are on average bigger but less mobile than female, both when it comes to active and passive range of motion, and that left hand has statistically greater hand's span than the right one. Interestingly enough there is research suggesting that more sesamoid bones occur both in females than males and in the left hand compared to the right hand $[3,14-16,20]$.

This research focused on the sesamoid bones, due to them being one of the most morphologically variable structures of the human hand as well as sesamoid bones starting to ossify at the beginning of the puberty, which would be between 11 and 13 years of age for females and between 13 and 15 age for males [21], which seem to overlap with the typical beginning of the intense musical training for future students of the musical universities.

There was no significant difference between the groups of musicians and non-musicians regarding the amount of the sesamoid bones in the hand, as well as there was only approximately $12 \%$ difference between the groups in the symmetry which lines up with Miller's opinion [11] that there are no morphological differences in the structures of the hand. However, upon a closer inspection, there appears to be a tendency in the sesamoids' volume. It seems that musicians tend to have bigger sesamoid bones on average than non-musicians. The mean sum of all the sesamoid bones in one hand was 83.2351 $\mathrm{mm}^{3}$ in the study group compared to $74.8420 \mathrm{~mm}^{3}$ in the control group, which does meet the criteria of statistical significance ( $p$-value of the Fisher's test $=0.034<0.05$ ). When, in order to remove the potential confounding variable, the results were accounted for body type by dividing by body mass index of each participant, the $p$-value only decreased, further underlining the results.

There also seems to be a noticeable tendency regarding sexual dimorphism. Despite general tendency for women to have more sesamoid bones than men $[3,9,20,25]$, the men in the musicians' group proved to have statistically significantly ( $p$-value $=0.003094$ ) bigger sum of the volume of the sesamoid bones in one hand than women. Such dimorphism did not occur in the group of non-musicians 
( $p$-value $=0.636599)$. The participants were questioned regarding their history of past regular physical activity, and the suspected reason for such phenomenon could not be found, therefore it needs to be assumed that the primary reason for aforementioned dimorphism was the musical training.

Considering that both groups consisted of people in similar age (mean: 23.7 years for the study group and 22.8 years for the control group), and similar built (mean height: $172.8 \mathrm{~cm}$ for the study group and $174.3 \mathrm{~cm}$ for the control group, mean weight: $67.3 \mathrm{~kg}$ for the study group and $69.2 \mathrm{~kg}$ for the control group) with very small differences that could only possibly favour the control group (statistically bigger body mass should translate for the bigger mass of the skeletal structures), and that the sexual make-up of the control group was proven not to influence the outcome (no significant sexual dimorphism in the control group), it could be speculated that the main reason for the differences in the mean sum of the volume of the sesamoid bones was the musical training during the age of sesamoids' ossification. It would agree with the assumption that the sesamoid bones function as a pulley for the muscular tendons, therefore making the movement faster, stronger and safer for the joint underneath $[2,3,8,9,12,22,25]$. It could be speculated that the time when the hand undergoes most significant morphological adaptation to the task of playing the keyboard instrument, and therefore possibly most important time for regular musical training is the time of sesamoids' ossification which starts during early stages of puberty.

This idea seems to be supported by the results of the Student's t-test between the age of the beginning of the musical education or length of the musical education and volume of the sesamoid bones. This was tested on 27 out of 32 musicians due to limited availability of the information. However, this should not have an impact on the results since the sexual proportion remained the same. The length of education varied from 7 to 29 years with a mean of 15.4 years. The beginning age varied from 4 to 13 years of age with a mode of 6 mean of 7.7 years of age. In both cases the $p$-value of the test showed to be $p<0.0001$ which would suggest a very strong correlation.

Another interesting outcome of this research was finding of the unusually shaped sesamoid bone in the interphalangeal joint of the pollex. This bone, instead of typical oval shape, displayed two slight elevations on the palmar site, with a furrow between them. There

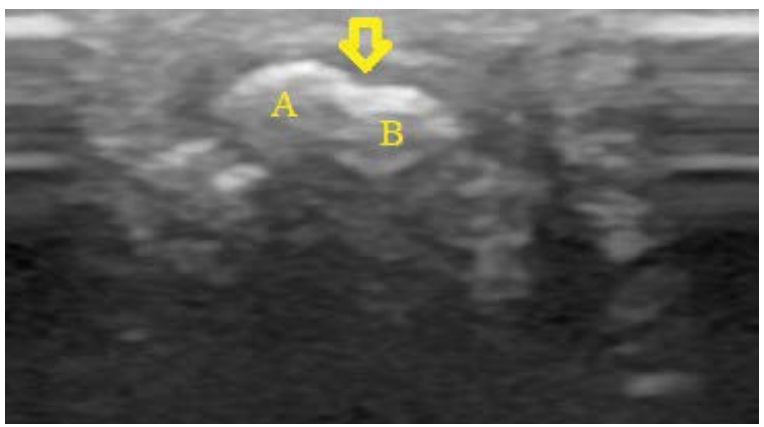

Figure 3. A "Bactrian" sesamoid bone found in the interphalangeal joint of the thumb of a female musician - horizontal view. There are two distinctive elevations $(A, B)$ and a sulcus between them (arrow).

was no proof that such "Bactrian" sesamoid occurred due to damage, or conjunction of two smaller bones, moreover similar sesamoid bones were observed by Jones [7] in smaller mammals, such as rabbits. Since there were 8 cases of such sesamoid found in the study group ( $25 \%$ of cases), most of which symmetrical (6 cases), and only 1 case in the control group (3\% of cases) it could be speculated that this variability is also a form of adaptation to the musical training on the keyboard instrument, especially since there is evidence that the sesamoid bones are being shaped by the action of the tendons above them (Fig. 3) [6].

Interestingly, all of the cases of "Bactrian" sesamoid occurred in female hands only. It might be related to the fact that the pattern of sesamoids' development in females seems to be tied to menarche [21]. Unfortunately, this concept is unverifiable based on this particular research.

\section{CONCLUSIONS}

There were no significant differences in the amount or localisation of the sesamoid bones of the hand between the musicians and the non-musicians.

The trained keyboard musicians tend to have significantly bigger sesamoid bones than non-musicians. It may be related to the fact that both sesamoid ossification and typical beginning of musical training intensification happens at the early stages of puberty.

There seems to be a strong correlation $(p<$ $<0.0001$ ) between the age of the beginning of the musical education or length of the musical education and volume of the sesamoid bones.

The male musicians proved to have significantly bigger sesamoid bones than the female musicians. Such tendency did not occur in the control group. 
Unusually shaped "Bactrian" sesamoid bone on the interphalangeal joint of the pollex was observed 8 times in the musicians' group and only once in the control group. All the cases occurred in the female's hand.

\section{REFERENCES}

1. Becciolini M, Bonacchi G. Fracture of the sesamoid bones of the thumb associated with volar plate injury: ultrasound diagnosis. J Ultrasound. 2015; 18(4): 395-398, doi: 10.1007/s40477-015-0166-1, indexed in Pubmed: 26550076.

2. Chen W, Cheng J, Sun R, et al. Prevalence and variation of sesamoid bones in the hand: a multi-center radiographic study. , ;8(7):-. Int J Clin Exp Med. 2015; 8(7): 11721-11726, indexed in Pubmed: 26380010.

3. Dąbrowski K, Stankiewicz-Jóźwicka H, Kowalczyk A, et al. Ossa Sesamoidea - prevalence of sesamoid bones in human hands. Folia Morphol. 2019 [Epub ahead of print], doi: 10.5603/FM.a2019.0123, indexed in Pubmed: 31750538.

4. Donison C. Hand Size vs the Standard Piano Keyboard. Med Problems Performing Artists. 2000; 15(3): 111-114, doi: 10.21091/mppa.2000.3022.

5. Egerci OF, Kose O, Turan A, et al. Prevalence and distribution of the fabella: a radiographic study in Turkish subjects. Folia Morphol. 2017; 76(3): 478-483, doi: 10.5603/ FM.a2016.0080, indexed in Pubmed: 28026849.

6. Jin $Z W$, Shibata $S$, Abe $H$, et al. A new insight into the fabella at knee: the foetal development and evolution. Folia Morphol. 2017; 76(1): 87-93, doi: 10.5603/ FM.a2016.0048, indexed in Pubmed: 27665955.

7. Jones FW. The principles of Anatomy as seen in hand. 2nd ed. Bailliere Tindall and Cox 1944.

8. Koo BS, Song Y, Sung YK, et al. Prevalence and distribution of sesamoid bones in the hand determined using digital tomosynthesis. Clin Anat. 2017; 30(5): 608-613, doi: 10.1002/ca.22881, indexed in Pubmed: 28340518.

9. Kose O, Guler F, Turan A, et al. Prevalence and distribution of sesamoid bones of the hand: a radiographic study in turkish subjects. Int J Morphol. 2012; 30(3): 1094-1099, doi: 10.4067/s0717-95022012000300055.

10. Kwon HH, Koo BS, Song Y, et al. AB1028 Prevalence and distribution of sesamoid bones in the hand determined using digital tomosynthesis. Abstracts Accepted for Publication. Clin Anat. 2017; 30(5): 608-613, doi: 10.1136/ annrheumdis-2017-eular.4553.

11. Miller G, Peck F, Watson J. Pain disorders and variations in upper limb morphology in music students. Med Problems
Performing Artists. 2002; 17(4): 169-172, doi: 10.21091/ mppa.2002.4016.

12. Ozcanli $H$, Sekerci $R$, Keles $N$. Sesamoid disorders of the hand. J Hand Surg Am. 2015; 40(6): 1231-1232, doi: 10.1016/j.jhsa.2015.01.029, indexed in Pubmed: 25771478.

13. Rosengarten E. Occurence of Sesamoid bones in the hands of the Polish population. Folia Morphol. 1967; XXVI: 2.

14. Sakai N. Keyboard span in old musical instruments: concerning hand span and overuse problems in pianists. Med Problems Performing Artists. 2008; 23(4): 169-171, doi: 10.21091/mppa.2008.4034.

15. Sang-Hie L. Hand biomechanics in skilled pianists playing a scale in thirds. Med Problems Performing Artists. 2010; 25(4): 167-174, doi: 10.21091/mppa.2010.4034.

16. Sang-Hie L. Pianists' hand ergonomics and touch control. Med Problems Performing Artists. 1990; 5: 72-78.

17. Seki $Y$, Hoshino $Y$, Kuroda $H$. Locking of the ring finger at proximal interphalangeal joint due to a sesamoid bone: a case report. Hand (N Y). 2012; 7(1): 119-120, doi: 10.1007/s11552-011-9386-9, indexed in Pubmed: 23450978.

18. Seki Y, Hoshino Y, Kuroda H. Prevalence of sesamoid bones in the interphalangeal joint of the thumb and fingers: a radiographic study. Clin Anat. 2013; 26(7): 823-826, doi: 10.1002/ca.22201, indexed in Pubmed: 23255267.

19. Sokołowska-Pituchowa J, Miaśkiewicz C. The Sesamoid bones in Negros. Folia Morphol. 1969; XXVIII: 2.

20. Sokołowska-Pituchowa J, Miaśkiewicz C. Studies on the Sesamoid bones in the hands of women. Folia Morphol. 1967; XXVI: 1.

21. Szmurło J, Szwaykowski W, Olczak A. Time of appearance of the ossification centre in the metacarpophalangeal sesamoid bone of the thumb in girls during puberty. Folia Morphol. 1975; XXXIV(3): 259-265.

22. Ting L, San C, Ben Ng, et al. Distribution of sesamoid bones in the hand: a study in the Chinese population. J Orthopaedics Trauma Rehabilitation. 2017; 23(1): 45-48, doi: 10.1016/j.jotr.2017.03.001.

23. Versalis A, De HuA, Garrison DH. De Humani Corporis Fabrica Libri Septem - An annotated translation of 1542 and 1555 editions. Garrison DH., Hast MH., Karger 2014.

24. Wristen BG, Jung MC, Wismer A, et al. Assessment of muscle activity and joint angles in small-handed pianists: a pilot study on the 7/8-sized keyboard versus the full-sized keyboard. Med Problems Performing Artists. 2006; 21(1): 3-9, doi: 10.21091/mppa.2006.1002.

25. Yammine K. The prevalence of the sesamoid bones of the hand: a systematic review and meta-analysis. Clin Anat. 2014; 27(8): 1291-1303, doi: 10.1002/ca.22378, indexed in Pubmed: 24615762. 